\title{
MAPEAMENTO TECNOLÓGICO DE PEDIDOS DE PATENTES RELACIONADOS À UTILIZAÇÃO DAS MICROALGAS
}

\author{
Kamila Cavalcante Dos Santos ${ }^{1}$, Jessica Guimarães Lopes ${ }^{2}$, Andréia Alves Costa ${ }^{3 *}$ \\ 1,2,3 Universidade de Brasília, DF, Brasil.
}

Rec.:14/07/2017. Ace.:18/12/2017

\section{RESUMO}

A dependência energética de combustíveis derivados do petróleo e os problemas ambientais ocasionados pelo seu uso despertou o interesse da sociedade por buscar combustíveis renováveis que possam suprir as demandas energéticas. Nesse contexto, microalgas são uma fonte promissora e alternativa para a obtenção de biodiesel. Esses microrganismos são caracterizados pelo seu rápido crescimento, alto conteúdo lipídico e por contribuir para a captura de dióxido de carbono.O presente trabalho tem como objetivo analisar as buscas de patentes relacionadas a utilização de microalgas com o auxílio da ferramenta de dados Questel Orbit, utilizando a palavra microalgas no campo de busca da base de dados. Para a realização da prospecção foram encontrados 219 depósitos de patentes relacionadas às microalgas a nível mundial sendo a maioria dos depositos classificados na seção C (Química e Metalurgia) tendo o Brasil e os Estados Unidos como principais depositantes.

Palavras-chave: Microalgas,Analise de patentes, Prospecção tecnológica

\section{TECHNOLOGICAL MAPPING OF PATENT APPLICATIONS IN MICROALGAE}

\begin{abstract}
The energy dependency of oil-derived fuels and environmental problems caused by your use of the company interest awakened by pick up renewable fuels that can meet the energy demands. In this context, microalgae are a promising and alternative source for biodiesel. These micro-organisms are characterized by rapid growth, your high lipid content and for contributing to the capture of carbon dioxide. This study aims to analyze the patent searches related to use of microalgae using data tool Questel Orbit, using the keyword microalgae in the search field of the database. For the realization of exploration for deposits found 219 patents related to microalgae worldwide with the majority of the deposits placed in section C (chemistry and Metallurgy) and the Brazil and the United States as major depositors.
\end{abstract}

KEYWORDS: Microalgae, patent analysis, technological Forecasting. 


\section{INTRODUÇÃO}

O Brasil possui um grande potencial para a utilização de fontes limpas de energia que possam preservar a sustentabilidade econômica e ambiental. A viabilidade ambiental e a elevação dos preços dos combustíveis fósseis favorecem a expansão dos combustíveis derivados de biomassa (FRANCO et al, 2013).

As microalgas possuem um grande diferencial para a produção de combustíveis, por sua capacidade de produzir uma grande quantidade de biomassa por unidade de área e tempo. Algumas microalgas possuem um alto nível de lipídeos que podem ser transformados em biodiesel a partir do processo de transesterificação (AZEREDO,2012).

As microalgas são organismos fotossintéticos que para um bom crescimento necessitam de luz solar, carbono, macro nutrientes e micronutrientes. São organismos similares às plantas e podem ser encontrados em meio marinho, em água doce e no solo (PLÁ, 2012). Por possuírem uma estrutura unicelular que permite a fácil conversão de energia solar em energia química, e essa característica pode ser aproveitada comercialmente para a produção de biomassa (AZEREDO, 2012)

Por apresentar um bom rendimento energético, diversas pesquisas têm sido realizadas com as microalgas no setor de produção de biomassa (EMBRAPA, 2016). Nesse sentido, estudos prospectivos vêm sendo realizados sobre diversos assuntos como uma tentativa de mapear o futuro, criando projeções que possam auxiliar na tomada de decisões.

Ao considerar a importância da utilização de fontes limpas de energia, assim como a importância de se entender as tendências tecnológicas que podem apoiar decisões relacionadas a pesquisa e desenvolvimento tecnológico (P\&D), este estudo analisará a situação das tecnologias de produção do biodiesel a partir de microalgas no Brasil, buscando a realização de um estudo prospectivo sobre o assunto.

A produção de microalgas constitui uma vertente mais recente e ainda crescente no cultivo das algas. As principais espécies que estão sendo cultivadas pertencem aos gêneros Arthrospira (Spirulina) e Chlorella, e podem ser cultivadas para diversas finalidades como produção de pigmentos e antioxidantes. Entretanto o cultivo de microalgas em larga escala para a produção de biocombustiveis como o biodiesel e o etanol ainda não é economicamente viável (EMBRAPA, 2016)

O desenvolvimento de um país é acompanhado pelo surgimento de novas tecnologias que buscam inovação e melhoria. A sociedade precisa estar preparada para o dinamismo que as descobertas tecnológicas proporcionam. O conhecimento tecnológico pode diecionar as tomadas de decisões definindo possiveis rotas a serem seguidas. Segundo Kupfer e Tigre (2004) "a prospecção recnológica pode ser definida como um meio sistemático de mapear os desenvolvimentos científicos e tecnologicos futuros capazes de influenciar de forma significativa uma indústria, a economia ou a sociedade como um todo." A realização de um estudo prospectivo podem identificar tecnologias emergentes.

O mundo encontra-se em constante transformação e as técnicas prospectivas surgem como base para se obter uma visão do que poderá acontecer. A prospecção tecnológica pode ser de grande valia para um melhor gerenciamento dos gastos, tanto públicos quanto privados, uma vez que pode mostrar se algum processo pode ser viável ou não. Assim, evita-se o desperdício de dinheiro antes de se investir 20 financeiramente em algo, visto que já foi realizado um estudo sobre aquele determinado tema.

SANTOS, K.C. dos.; LOPES, J.G.; COSTA, A.A.. Mapeamento tecnológico de pedidos de patentes relacionados à utilização das microalgas. 
Existem quatro atitudes possíveis ao se tratar de uma mudança tecnológica. A primeira delas é a atitude pós-ativa na qual a sociedade apenas sofre as consequências das mudanças. A segunda é a atitude reativa na qual só depois de ocorrido algum fato é que a organização reage. A terceira é a atitude pré ativa, na qual existe uma preparação para as mudanças que ocorrerão e a ultima é a atitude pró ativa, na qual as mudanças são promovidas pela própria sociedade(GODET, 2000). Observa-se que no caso da prospecção tecnologia a atitude tomada é uma atitude pré ativa, na qual a sociedade pode se preparar para as mudanças que uma determinada tecnologia pode trazer através da busca por informações.

No contexto de que as microalgas podem ser utilizadas em diversas aplicações este trabalho tem como objetivo geral fazer um mapeamento da utilização das microalgas visando identificar os principais depositantes a nivel mundial apresentando um panorama do mercado de microalgas e identificando os países que mais depositam patentes sobre o assunto.

\section{METODOLOGIA}

A metodologia desse trabalho consiste em uma pesquisa utilizando a base de dados Questel Orbit utilizou, essa base de dados cobre publicações de patentes de 90 escritorios nacionais e 6 escritórios regionais. As publicações são agrupadas em famílias de patentes, essa base de dados oferece também acesso aos PDFs de pedidos de patentes de mais de 40 países (AXONAL, 2015)

A palavra chave definida para busca na ferramenta computacional foi microalgas, as patentes que possuiam microalgas no título e/ou resumo foram agrupadas e com o auxílio do atalho analyze disponibilizado no orbit fora, feitas as analises.

As analises realizadas com o auxilio da ferramenta foram para auxiliar na identificação dos princiapis depositantes, principais países depositantes, principais utilizações das microalgas, evolução temporal e cobertura geográfica. Os dados gerados pelo orbit foram interpretados e analisados.

\section{RESULTADOS E DISCUSSÕES}

Foram encontrados 219 patentes relacionadas a palavra-chave microalgas em caráter mundial desde 1997 a 2017 tendo em vista que a ferramenta orbit resgata documentos depositados em até 20 anos.

Ao analisar os dados fornecidos pelas patentes disponibilizadas percebe-de que o depósito de patentes relacionadas as microalgas começou a ter um aumento a partir do ano de 2008. O ápice das publicações foi em 2014 com 36 depósitos.Após o ano de 2014 houve uma queda na quantidade de publicações como pode ser verificado na figura 1. Esses dados permite constatar que as pesquisas sobre microalgas ainda é algo recente que está em fase de desenvolvimento, se comparado com os depositos de patentes de outros assuntos ainda se tem poucas patentes sobre microalgas.

SANTOS, K.C. dos.; LOPES, J.G.; COSTA, A.A.. Mapeamento tecnológico de pedidos de patentes relacionados à utilização das microalgas. 
Figura 1- Evolução do número de depósitos de patentes relacionadas a microalgas no mundo.

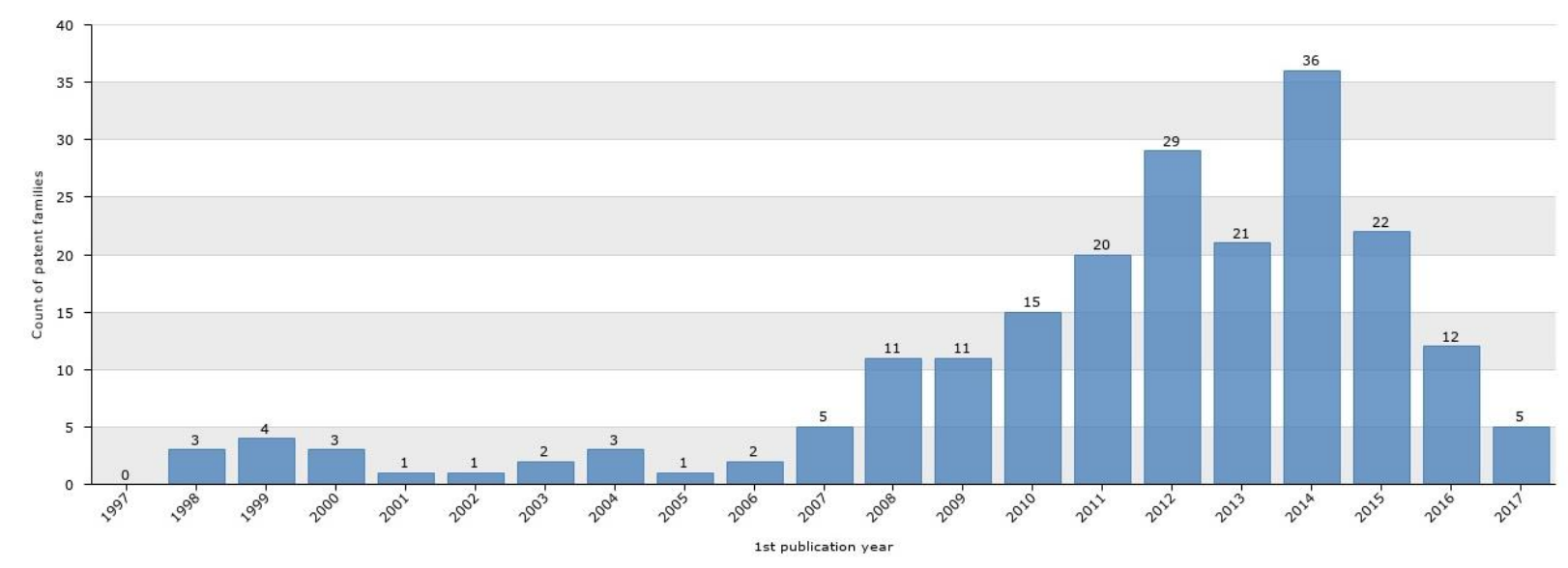

(9) Questel 2017

Fonte: Questel Orbit, 2017

Na figura 2 relaciona os principais depositantes de patentes relacionadas as microalgas, a Roquette Freres que é uma empresa francesa enconta-se em destaque com o maior número de famílias de patentes depositadas. Observa-se também que a PETROBRAS tem patentes depositadas e que o deposito de patentes não se restringe somente a empresas, é possivel observar que algumas universidades também depositam patentes, isso se dá devido ao fato de que as universidades investem em pesquisa e essas pesquisas geram o descobrimento e/ou aperfeiçoamento das tecnologias

Figura 2- Principais depositantes

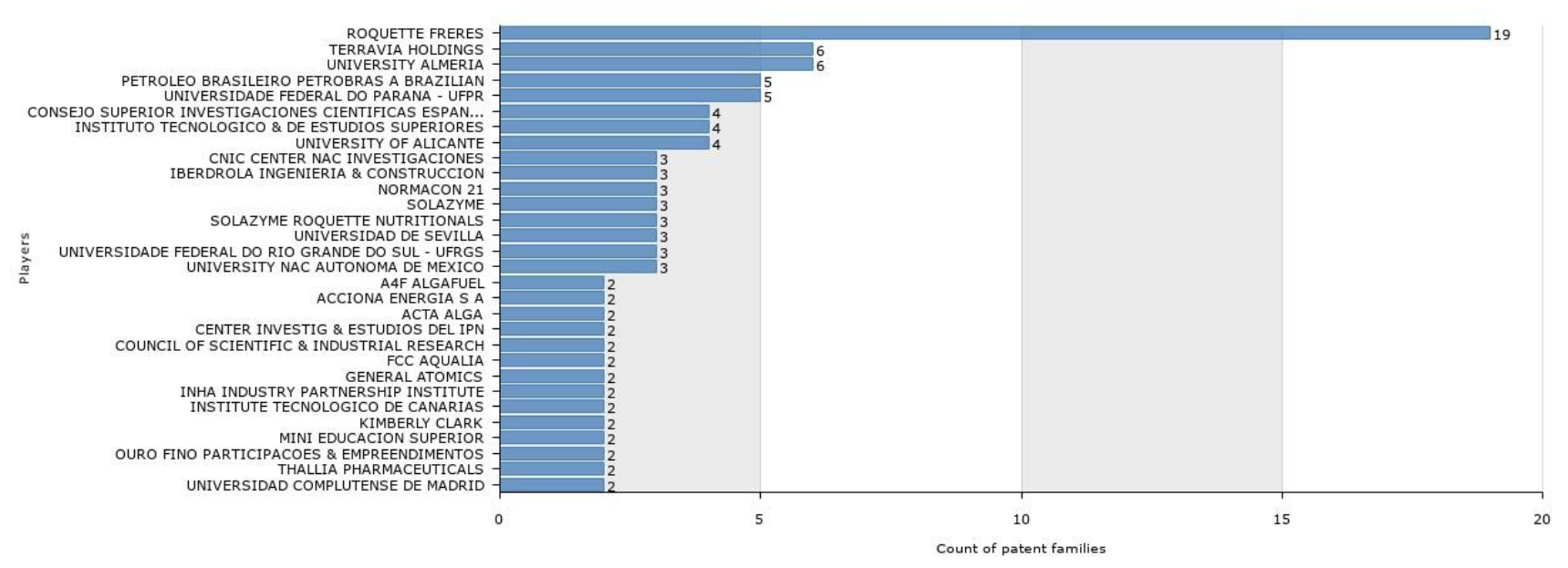

(9) Questel 2017

Fonte: Questel Orbit, 2017

SANTOS, K.C. dos.; LOPES, J.G.; COSTA, A.A.. Mapeamento tecnológico de pedidos de patentes relacionados à utilização das microalgas. 
A figura 3 mostra a relação do número de patentes depositadas para cada classificação Internacional de Patentes (IPC). A classificação IPC é um sistema de classificação das patentes por simbolo de acordo com as diferentes áreas tecnologicas a que pertencem. A partir da analise da figura 4 pode-se observar que o maior número de patentes de microalgas estão depositadas na categoria $\mathrm{C} 12 \mathrm{~N}$ 001/12 com 88 patentes seguida pela catergoria C12M-001/00 com 48 patentes. Percebe-se que a maioria das patentes estão classificadas na Seção C que diz respeito a Química e Metalurgia.

Figura 2- Quantidade de publicações de acordo com a classificação IPC

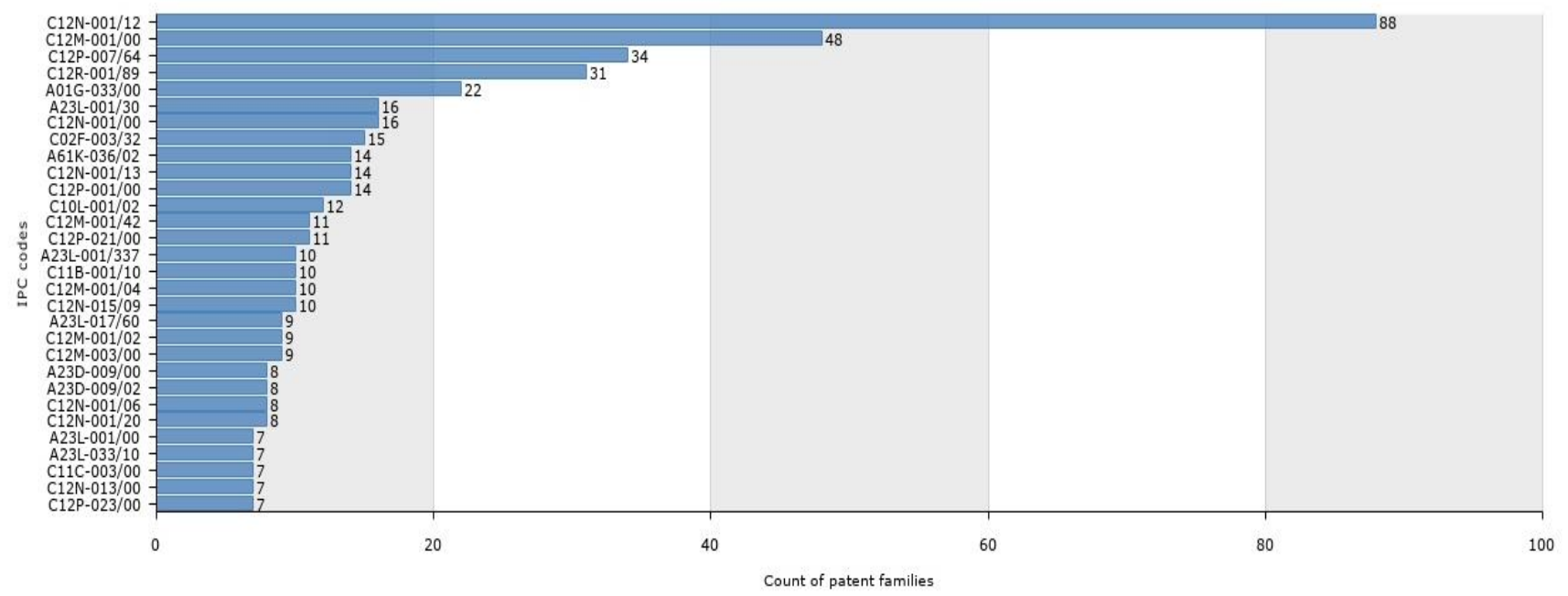

(๑) Questel 2017

Fonte: Questel Orbit, 2017

O quadro 1 apresenta a descrição das subclasses do sistema de classificação IPC e a partir dela podemos verificar quais estão sendo as aplicações mais usuais com as microalgas. Percebe-se que o número maior de registos em patentes nesse assunto está relacionado com o meio de cultura das algas, aparelhos para microbiologia e óleos graxos. Pode-se perceber também a variedade das subclasses de patentes e isso é um indicador de que as microalgas são utilizadas para diversas aplicações desde produção de biocombustiveis até produtos alimenticios.

Quadro 1- Classificação internacional de patentes

\begin{tabular}{|l|l|l|}
\hline Classificação IPC & Numero de depositos & Descrição \\
\hline C12N-001/12 & 88 & $\begin{array}{l}\text { Meio de cultura de algas } \\
\text { unicelulares }\end{array}$ \\
\hline C12M-001/00 & 48 & $\begin{array}{l}\text { Aparelhos para enzimiologia } \\
\text { ou microbiologia }\end{array}$ \\
\hline C12P-007/64 & 34 & Óleos graxos \\
\hline C12R-001/89 & 31 & Algas \\
\hline A01G-033/00 & 22 & Cultivo de algas \\
\hline
\end{tabular}

SANTOS, K.C. dos.; LOPES, J.G.; COSTA, A.A.. Mapeamento tecnológico de pedidos de patentes relacionados à utilização das microalgas. 


\begin{tabular}{|c|c|c|}
\hline A23L-001/30 & 16 & Produtos alimentícios \\
\hline $\mathrm{C} 12 \mathrm{~N}-001 / 00$ & 16 & $\begin{array}{l}\text { Processos de propagação, } \\
\text { manutenção ou conservação } \\
\text { de micro-organismos ou suas } \\
\text { composições }\end{array}$ \\
\hline $\mathrm{CO} 2 \mathrm{~F}-003 / 32$ & 15 & $\begin{array}{l}\text { Tratamento de águas } \\
\text { residuais com algas }\end{array}$ \\
\hline A61K-036/02 & 14 & Finalidades médicas \\
\hline C12N-001/13 & 14 & Modificação genética \\
\hline C12P-001/00 & 14 & $\begin{array}{l}\text { Processos gerais para a } \\
\text { preparação de compostos } \\
\text { ou composições que } \\
\text { utilizam micro-organismos } \\
\text { ou enzimas }\end{array}$ \\
\hline C10L-001/02 & 12 & $\begin{array}{lr}\text { Combustiveis } & \text { carbonaceos } \\
\text { liquidos } & \text { baseados } \\
\text { essencialmente } & \text { em } \\
\text { componentes } & \text { consistindo } \\
\text { somente em } & \text { carbono, } \\
\text { hidrogênio, e oxigênio }\end{array}$ \\
\hline C12M-001/42 & 11 & $\begin{array}{l}\text { Aparelhos para o tratamento } \\
\text { de micro-organismos ou } \\
\text { enzimas com energia elétrica } \\
\text { ou ondulatória }\end{array}$ \\
\hline C12P-021/00 & 11 & $\begin{array}{l}\text { Preparação de peptídeos ou } \\
\text { proteínas }\end{array}$ \\
\hline A23L-001/00 & 10 & Algas marinhas comestíveis \\
\hline C11B-001/10 & 10 & $\begin{array}{l}\text { Produção de gorduras ou } \\
\text { óleos graxos a partir de } \\
\text { matérias primas por } \\
\text { extração. }\end{array}$ \\
\hline C12M-001/04 & 10 & $\begin{array}{lr}\text { Aparelhos } & \text { para } \\
\text { enzimologia } & \text { ou } \\
\text { microbiologia com meios } & \text { para introdução de gás }\end{array}$ \\
\hline C12N-015/09 & 10 & $\begin{array}{lcr}\text { Mutação } & \text { genética } & \text { com } \\
\text { tecnologia } & \text { do } & \text { DNA } \\
\text { recombinante } & & \\
\end{array}$ \\
\hline A23L-017/60 & 9 & Algas marinhas comestiveis \\
\hline C12M-001/02 & 9 & $\begin{array}{l}\text { Aparelhos para enzimiologia } \\
\text { ou microbiologia com meios } \\
\text { de agitação }\end{array}$ \\
\hline C12M-003/00 & 9 & $\begin{array}{l}\text { Aparelhos para cultura de } \\
\text { plantas }\end{array}$ \\
\hline A23D-009/00 & 8 & $\begin{array}{l}\text { Outros óleos ou gurduras } \\
\text { comestiveis }\end{array}$ \\
\hline A23D-009/02 & 8 & $\begin{array}{l}\text { Outros óleos ou gurduras } \\
\text { comstiveis caracterizado pela } \\
\text { produção ou preparação }\end{array}$ \\
\hline $\mathrm{C} 12 \mathrm{~N}-001 / 06$ & 8 & Lises de micro-organismos \\
\hline $\mathrm{C} 12 \mathrm{~N}-001 / 20$ & 8 & Meio de cultura \\
\hline
\end{tabular}

SANTOS, K.C. dos.; LOPES, J.G.; COSTA, A.A.. Mapeamento tecnológico de pedidos de patentes relacionados à utilização das microalgas. 


\begin{tabular}{|l|l|l|}
\hline A23L-001/00 & 7 & $\begin{array}{l}\text { Preparo ou tratamento de } \\
\text { alimentos }\end{array}$ \\
\hline A23L-033/10 & 7 & $\begin{array}{l}\text { Modificaços na qualidade } \\
\text { nutritiva de alimentos usando } \\
\text { aditivos }\end{array}$ \\
\hline C11C-003/00 & 7 & $\begin{array}{l}\text { Gorduras, óleos ou ácidos } \\
\text { graxos resultantes da } \\
\text { modificação química de } \\
\text { gorduras, óleos, ou ácidos } \\
\text { graxos } \\
\text { Tratamento de } \\
\text { microrganismos ou enzimas } \\
\text { com energia elétrica ou } \\
\text { ondular }\end{array}$ \\
\hline C12P-023/00 & 7 & $\begin{array}{l}\text { Preparação de compostos } \\
\text { contendo um anel } \\
\text { ciclohexeno tendo uma } \\
\text { cadeia lateral insaturada } \\
\text { contendo pelo menos dez } \\
\text { átomos de carbono ligados } \\
\text { por duplas ligações } \\
\text { conjugada }\end{array}$ \\
\hline
\end{tabular}

Fonte: (INPI, 2017)

A figura 3 mostra a distribuição geograficas das patentes depositadas e pode-se verificar que o Brasil, Estados Unidos, Espanha e França possuem os maiores números de patentes depositadas sobre tecnologia de utilização de microalgas. O continente africano e outros paises representados no mapa ainda não possuem patentes nessa área de pesquisa.

Figura 3- Cobertura geográfica das patentes

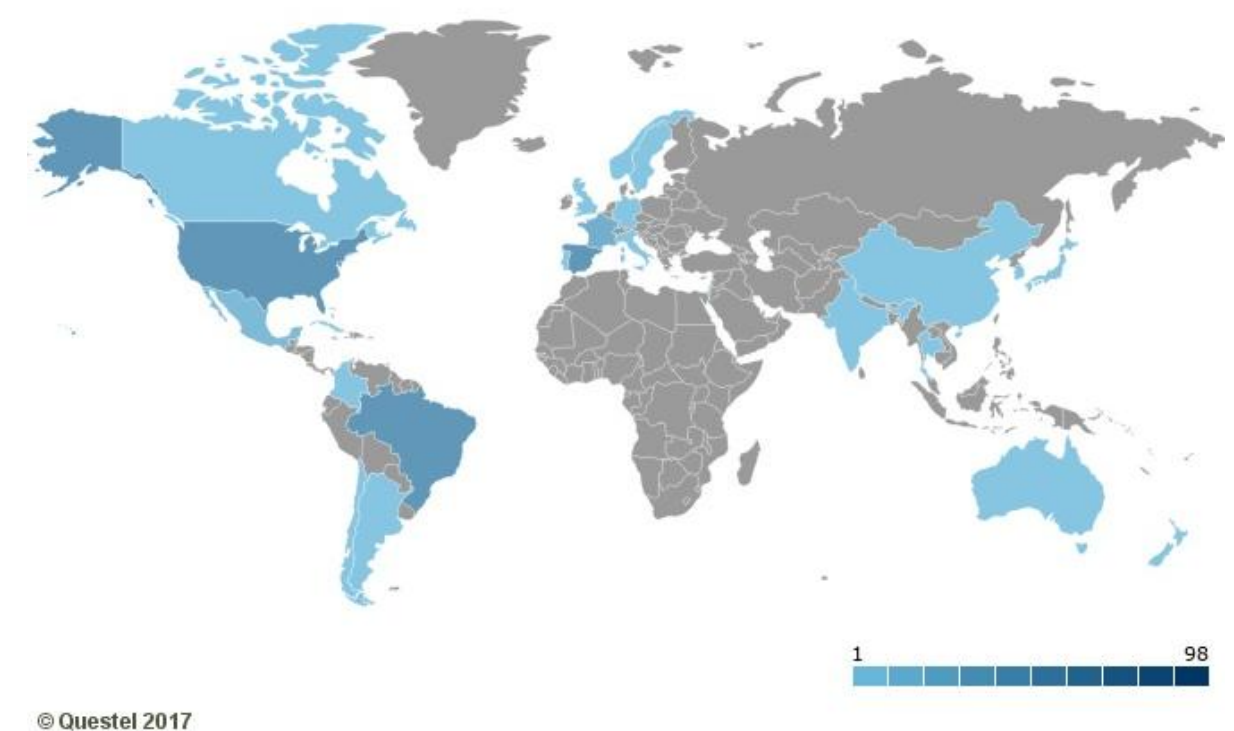

Fonte: Questel Orbit, 2017

SANTOS, K.C. dos.; LOPES, J.G.; COSTA, A.A.. Mapeamento tecnológico de pedidos de patentes relacionados à utilização das microalgas. 
A figura 4 mostra a distribuição das patentes por conceitos e pode-se perceber os diversos ramos de desenvolvimento das patentes sobre microalgas.As patentes incluem processos de melhorias em fotobiorreatores por exemplo que faz parte dos métodos de cultivo das microalgas. Também se verifica patentes relacionadas a biomassa, centrifugação que é um método de colheita dessa biomassa. É um universo muito amplo já que as microalgas podem ser utilizadas na industria farmaceutica, energetica, alimenticia entre outras.

Figura 4- Distribuição dos resultados da pesquisa por conceitos.

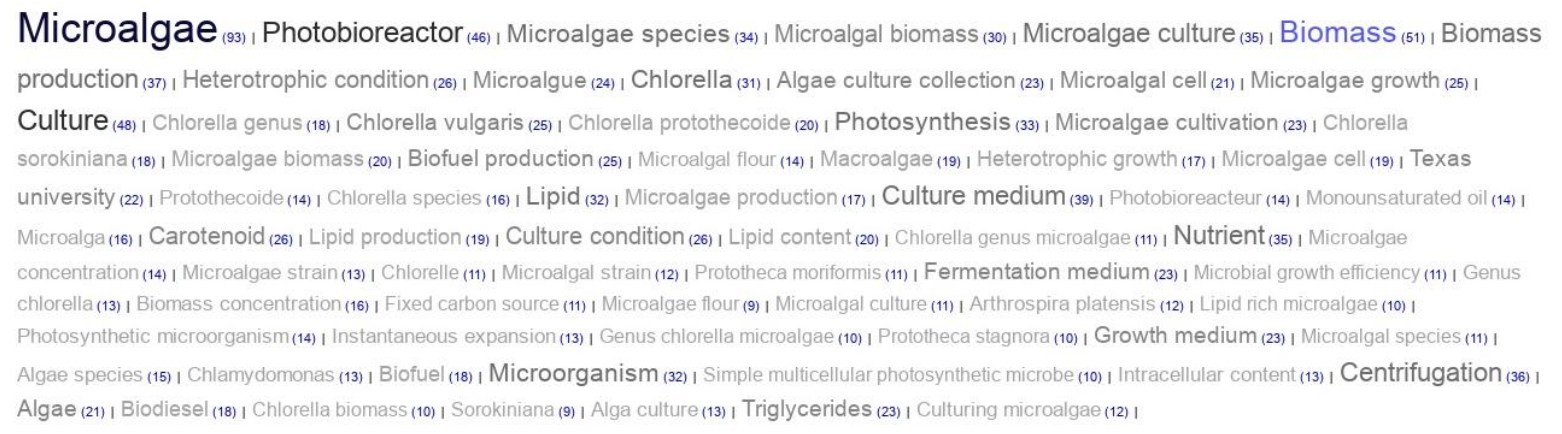

๑Questel 2017

Fonte: Questel Orbit, 2017

\section{CONCLUSÃ0}

Essa tecnologia de produção de biodiesel a partir de microalgas ainda é algo recente e o custo da produção de biomassa microalgal é caro quando comparado com outras oleaginosas. Nesse contexto, ao analisar os resultados obtidos da busca de patentes observa-se que as tecnologias que estão sendo patenteadas visam otimizar o cultivo, a produção de lipideos e até mesmo a utilização de modificação genética nessas microalgas. $\mathrm{O}$ mercado das microalgas não converge apenas para a produção de biocombustiveis, o mercado farmaceutico e alimenticio também é bem difundido.

O Brasil foi um dos paises destaques no número de patentes publicadas sobre microalgas e isso mostra o interesse do país por esse tipo de tecnologia e que pode proporcionar pesquisa e consequente surgimento de novas tecnologias que possam complementar ou otimizar as que ja existem.

A prospecção tecnológica de microalgas pode identificar alguma necessidade ou limite das tecnologias que estão sendo utilizadas, possibilitando também a identificação das aplicações mais usuais para as microalgas no cenário brasileiro e no mundo já que a utilização da mesma não se limita apenas para fins energéticos. A análise de patentes pode identificar as possibilidades de mercado e os mercados mais promissores.

SANTOS, K.C. dos.; LOPES, J.G.; COSTA, A.A.. Mapeamento tecnológico de pedidos de patentes relacionados à utilização das microalgas. 


\section{REFERÊNCIAS}

AXONAL, Consultoria Tecnológica Ltda. A empresa Questel. Orbit, Inc. 2015. Disponivel em: < http://www.ime.unicamp.br/>. Acesso em jul. 2017.

AZEREDO, V.B.S. Produção do biodiesel a partir do cultivo de microalgas: Estimativa de custos e perspectiva para o Brasil. 2012. 171f. Tese ( Mestrado em Planejamento Energético) - Universidade Federal do Rio de Janeiro.

EMBRAPA. Microalgas. Agroenergia em revista. Ano IV, n10,dezembro 2016.

FRANCO, André Luiz Custódio et al . Biodiesel de microalgas: avanços e desafios. Quím. Nova, São Paulo , v. 36, n. 3, p. 437-448, 2013

GODET, M. A "Caixa de Ferramentas" da Prospectiva Estratégica. ed. CEPES Centro de Estudos de Prospectiva e Estratégica. Lisboa, 2000 (Cadernos do Cepes) Disponível em: http://www.cnam.fr/lipsor/ lips/conferences/data/bolips-po.pdf

INPI, Instituto Nacional de Propriedade Industrial. Classificação de patentes. 2015. Disponível em:< http:// http://www.inpi.gov.br/menu-servicos/patente/classificacao-de-patentes > Acesso em jul. 2017.

KUPFER, D.; TIGRE, P. B. Prospecção tecnológica. In: CARUSO, L. A.; TIGRE, P. B. (Org.). Modelo SENAI de prospecção: documento metodológico . Montevideo: OIT/CINTERFOR, 2004.

PLÁ, Juan Algorta. Perspectivas do biodiesel no Brasil. Indicadores Econômicos FEE, v. 30, n. 2 , p. 179-190, 2002.

SANTOS, K.C. dos.; LOPES, J.G.; COSTA, A.A.. Mapeamento tecnológico de pedidos de patentes relacionados à utilização das microalgas. 